\title{
Facilitating Social Work Role Plays in Online Courses: The Use of Video Conferencing
}

\author{
Dale Fitch \\ Kelli Canada \\ Suzanne Cary \\ Rebekah Freese
}

\begin{abstract}
Role plays have served an instrumental role in social work education by providing opportunities for students to acquire interaction skills. This project tested various online video conferencing tools to facilitate role plays for students who live in different locations and who are unable to be at the same place at the same time. Key features of the technology included the ability to facilitate real-time interaction, compatibility with laptops and Wi-Fi connections, and the ability to record sessions for later viewing and feedback. Method: Case study design. Results: Students were able to use the videoconferencing software with minimal support. Video quality was not always ideal with contributing factors being the time of day students used the software. There were no distinguishable time and effort demands associated with the online video conferencing compared to classroom role plays. Some students found use of the technology caused them to feel disconnected from their peers compared to face-to-face encounters, while other students found the encounter more intimate in that the pressure to perform in front of others was not felt. Implications: Video conferencing is a promising tool to facilitate social work role plays. Future research needs to assess the acquisition of specific skills compared to traditional classroom students.
\end{abstract}

Keywords: Role plays; online education; online videoconferencing; social work education

Acquiring and practicing interaction skills is a perceived challenge as the social work profession embraces online education. Social work online education will continue to grow and develop, in large part, to the extent social work educators are successful in helping students acquire interaction skills. Whether the interaction skill is as basic as engaging a client, or as advanced as supporting a client in dealing with the ramifications of a traumatic event, all such capabilities hinge on our abilities as social work educators to provide a learning environment that is accessible and effective at teaching interaction skills to online students.

Our program rose to this challenge by testing various online video conferencing tools to facilitate role plays for students who live in different locations and are unable to be at the same place at the same time

On simulation game theory (Hargreaves \& Hadlow, 1997), social work education has a long history in using role plays, which are a means for new students to achieve a sense of self-awareness (Gardner, 2001) and self-efficacy (Petrovich, 2004), and to instruct students on interaction skills (Reid \& Hanrahan, 1982). Role plays are valuable tools to assess whether students are ready for practice (Duffy, Das, \& Davidson, 2013), to develop

Dale Fitch, PhD, is Associate Professor, Kelli Canada, PhD, LCSW is Assistant Professor, Suzanne Cary, MSW, LCSW is Clinical Instructor, and Rebekah Freese, MSW, LCSW is Clinical Instructor, School of Social Work, University of Missouri School of Social Work, Columbia, MO 65211. 
group work skills (Macgowan \& Vakharia, 2012), and to promote reflective learning, particularly when coupled with videotaped analysis (Bolger, 2014; Dempsey, Halton, \& Murphy, 2001). Various methods have been used to achieve pedagogical goals when employing role plays in the classroom. For example, Petracchi (1999) and Petracchi and Collins (2006) used actors to simulate client situations, and the results were largely positive. While role plays are typically viewed as a dyad exercise, Moss (2000) has used them in a large group format as well. The pedagogical goal was for students to experience multiple actors similar to what would be encountered when doing family therapy or engaged in a multi-agency collaborative project.

Some empirical studies have compared the efficacy of online role plays to face-to-face role plays with little difference found in student learning outcomes for acquiring problemsolving skills related to alcohol use (Vapalahti, Marttunen, \& Laurinen, 2013). On the other hand, regarding the learning setting, students in other studies prefered face-to-face experiences (Holmes \& Kozlowski, 2015). Related fields, such as counseling psychology, have also evaluated the efficacy of online training for clinicians needing to acquire Cognitive Behavioral Therapy (CBT) skills with promising results, especially when accessibility is a key issue (Rakovshik et al., 2013). Finally, in social work, Peterson (2014) reported significant improvement in clinical skills for students who used handheld digital recorders. Students uploaded role play files to a private YouTube channel for instructor feedback, eliminating the need to either email large media files or mail physical storage devices to the instructor in order to submit the assignment.

Cost can be a key consideration when online programs adopt new technology solutions. Online programs in general can be quite costly to design and implement with overhead costs ranging up to the millions of dollars (Miller, 2014). For example, some technology solutions involve the use of Artificial Intelligence to emulate unscripted conversational encounters (Zhang et al., 2009). While a promising approach, the costs associated with developing the programming language can be substantial. Other social work programs hire professional actors to perform role plays with online students (see http://www.backstage.com/casting/msw-online-education-role-plays-69125/). Lastly, unlike Peterson (2014), in which handheld devices and YouTube were used, other programs developed their own web servers for feedback and discussion of videos that were shot with two cameras and stored on a separate media server (Shibusawa, VanEsselstyn, \& Oppenheim, 2006). In addition to the costs associated with the equipment, the resulting high definition video files could only be accessed by students on campus or by those with access to broadband internet connections.

Studies examining the implementation and effectiveness of online delivery of content must consider whether the delivery is synchronous or asynchronous. Synchronous delivery means that students and instructors meet at the same time via videoconferencing software (e.g., Adobe Connect, Blackboard Collaborate, etc.) Asynchronous delivery means that students and instructors interact solely via discussion boards, recorded video lectures, or other multi-media content, with no real-time interaction. Online asynchronous programs could ask students to find a local friend with whom to perform a role play, videotape the encounter, and then email the video file to the instructor for feedback. Some online professional counseling programs, however, have no practice component until students are 
in their internships (Reicherzer et al., 2012) (i.e., students do not have any role play experiences). The distinction between synchronous and asynchronous delivery is a central consideration when identifying and evaluating the types of technology needed for online courses.

In sum, the literature provides numerous examples of the ways in which role plays can be incorporated into online education. However, most studies tend to skip over the thinking and design work that went into the actual technical solutions and focus only on group process issues like cohesion, presence, and therapeutic alliance (e.g., Holmes \& Kozlowski, 2015) when evaluating their efforts. Failing to document the design process is especially problematic when there are known technical issues that can be challenging in online verbal interactions, e.g., latency (when audio and video become out of sync). It is important to identify and describe the thinking and design work in order to assist other programs in adopting and implementing technology solutions that best address their desired delivery style. Within social work and similar programs teaching clinical skills, the technical solution has to address a difficult problem - examining the best way for online students to acquire interaction skills. Therefore, the purpose of this paper is to systematically examine the design features that need to be considered, that is, design choice, when developing a technical solution that facilitates online role plays.

\section{Proof of Concept Project}

The course delivery method for our school of social work is largely asynchronous except for the role play component. When doing role plays, our students interact with each other in real time; therefore, our program is a hybrid asynchronous/synchronous approach. To achieve this synchronous component within an overall asynchronous program, we proceeded as a proof of concept project since the goal was the development of a technology solution that we needed to test in terms of feasibility, cost, and scalability. That is, the technical aspects needed to work across various hardware components, (e.g., personal computers, laptops, smartphones); it needed to be accomplished at little to no cost; and it needed to be implementable in classes across the curriculum whether online or on campus. Key in our formulation of the technology solution is that the technology needed to align with our profession's commitment to training students with face-to-face interactions whenever possible. Specifically, one misconception with online education is that students are not able to interact with people in real time. Prior research likely contributes to this misconception, for example, studies in which role plays were evaluated by listening to taped phone conversations (e.g., Rakovshik et al., 2013) or occurred through text-only discussion forums (e.g., Levine, 2013).

In order to preserve real-time interactions, in 2013 project members began testing various online video conferencing tools. Key features needed to include: a) The ability to facilitate the real-time interaction of two students from different locations. Students learn in role plays by playing both the therapist and the client role. Indeed, it might be argued that playing the client role is instrumental in helping students develop empathic skills, b) The ability to work well with laptops and Wi-Fi/3G connections in rural settings. c) The ability to record the session for later viewing and feedback. We examined various online platforms that could have met these needs, but all of them came with price tags above our 
program means. We also examined the videoconferencing capabilities available through our learning management system, Blackboard. While financially feasible, it lacked the technical capabilities of being easily accessible across platforms (Windows and Macintosh), it required additional software downloads (Java, in particular), and the resulting recorded sessions displayed degraded video quality. After considerable testing and use, we decided to examine Google Hangouts (https://plus.google.com/hangouts) and Zoom (http://zoom.us/). Peer and instructor feedback was accomplished using videoANT (http://ant.umn.edu/) through the University of Minnesota.

\section{Methods}

Institutional Review Board approval was obtained since a portion of our evaluative data involved the display and review of recorded online interactions between students. Our sampling frame included students and instructors from three classes: an on-campus undergraduate course, an on-campus graduate class, and an online graduate class. In total, there were 3 instructors and 32 students who participated and provided feedback data. 35 instructor and student participants.

As a proof-of-concept, formative evaluation of a technology tool, we used the design science methodology outlined by Peffers, Tuunanen, Rothenberger, and Chatterjee (2008) for three main reasons: 1) The focus of this project is on how the software application for role plays was chosen and implemented. As such, the software as a technology artifact was designed to fit a specific function within organizational constraints. 2) This focus on the design features, in turn, produces design principles that can be implemented in other settings like other schools of social work. 3) These design principles, in turn, can serve as the basis for future theoretical and empirical research projects. A sampling of what those research questions may entail is discussed under Implications for Future Research. As outlined in Peffers and colleagues (2008), we discuss four central components of this project: process, resources, management, and effectiveness.

\section{Process}

Too often so-called technology solutions are presented as a one-and-done solution offered by vendors to schools of social work. Sometimes these solutions work, but oftentimes they do not. In either case, the faculty are left largely unaware as to how the solution actually works. In order to involve all key stakeholders in our technology adoption, participant recruitment, including instructors and students, unfolded in an iterative process. It began with the testing of various platforms among faculty, then soliciting feedback from a small number of students, and finally moving forward to classroom-level involvement. Each step of the process resulted in feedback that informed the next step.

We took this approach for several reasons. First, budgetary constraints prohibited the use of outside vendors to provide a technical solution. Second, we needed to be able to explain why a certain approach was chosen pedagogically and how it could fit into online classes but also be capable of use in the traditional classroom. Third, multiple instructors were involved to explore and test the technology. This is a strength as individual faculty members may identify a technology solution for a specific class, only to find out that it will 
not work for other classes or lacks broader buy-in from other instructors. This may result in the non-adoption of the technology solution on a broader scale.

\section{Resources}

This aspect of the analysis primarily examined the time and effort required to conduct and assess online role plays compared to the traditional classroom approach. Secondarily, we considered the resources that would be required in terms of classroom time utilization, technology demands, connection speeds, etc. Finally, costs were an integral aspect of the decision-making process to adopt a technology solution. Resource-deep universities appear to have the option of expending funds in trying out various technology solutions that are simply cost-prohibitive for many institutions. We needed to explore technology solutions that did not require upfront expenditures yet still met our pedagogical goals.

\section{Management}

The instructors were asked questions related to the feasibility of employing this technology on a wider scale if pilot results look promising. For example, the traditional classroom constrains the number of role plays that can be conducted and observed by the instructor within a given block of time. Online video conferencing does not have this constraint thereby potentially increasing the workload of instructors. Conversely, alternative methods of providing feedback may lessen this workload. The technology solution also needed to be one that did not have a steep learning curve and/or require the use of proprietary software that would require additional instructor obligations to learn and master.

\section{Effectiveness}

As a formative evaluation, any assessment of effectiveness is provisional, but useful information was gathered from the student and instructor participants regarding the utility of the technology artifact, the video quality of the role-play compared to classroom settings, and a preliminary understanding of the efficacy of this technology artifact to nurture interaction skills.

To elicit information related to these four dimensions, we asked the students and instructors via email or through face-to-face discussions the following questions:

1. How easy was it to use Google Hangouts/Zoom and provide feedback?

a. Did you experience any technical difficulties?

b. Were the directions easy to follow?

c. Was the video quality sufficient to perform a role play?

2. How would you compare the time and effort compared to a classroom role play?

3. Do you believe you were able to acquire social worker-client interaction skills comparable to a classroom role play? If so, how? If not, why not?

\section{Findings}

The methodological framework and research questions resulted in findings that fell within eight domains: the user interface, technical issues, costs, support needs, time and 
effort, skill acquisition, privacy issues, and evidence for transfer of learning. While Google Hangouts was proficient in meeting many of the pedagogical and technical requirements necessary for conducting role plays, Zoom was used because of the ease of use and video quality. As such, most of the findings refer to Zoom.

\section{Interface}

Perhaps the most significant factor in deciding upon any technology solution is the user interface experience. To aid in better understanding the user interface, two screen captures have been provided from actual student participants. The first image, used with permission, captures exactly what the users see when talking to each other via Zoom.

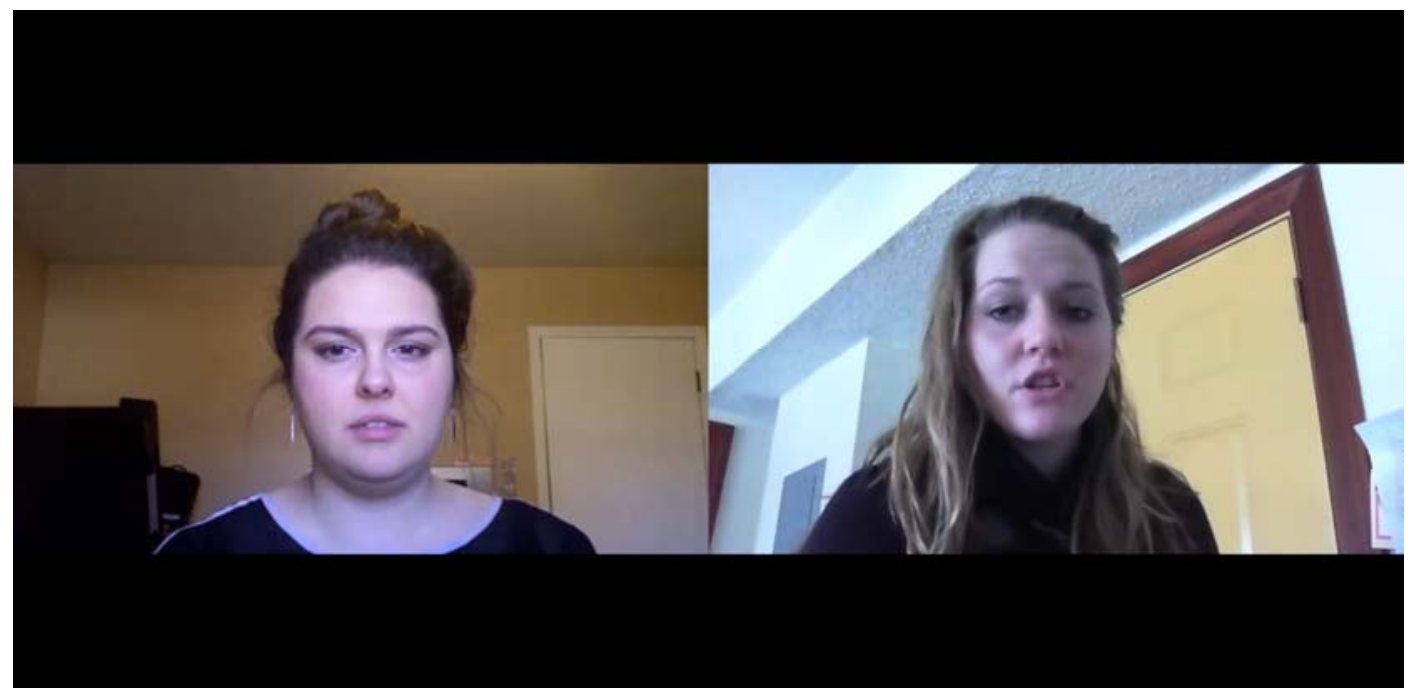

Figure 1. Screen capture of Zoom user interface.

It is immediately apparent that the user interface is not cluttered with extraneous technical tools thereby preserving the one-on-one experience. As an observer to the role play, one is able to see each participant head-on and not in profile view as occurs in classroom role plays. After the role play is concluded, one of the participants uploads the video (automatically stored on the user's device) to YouTube choosing the Unlisted privacy setting which means it can only be viewed if you have the specific link to the video. Once uploaded, the URL for the video is linked from videoANT resulting in the following user interface: 


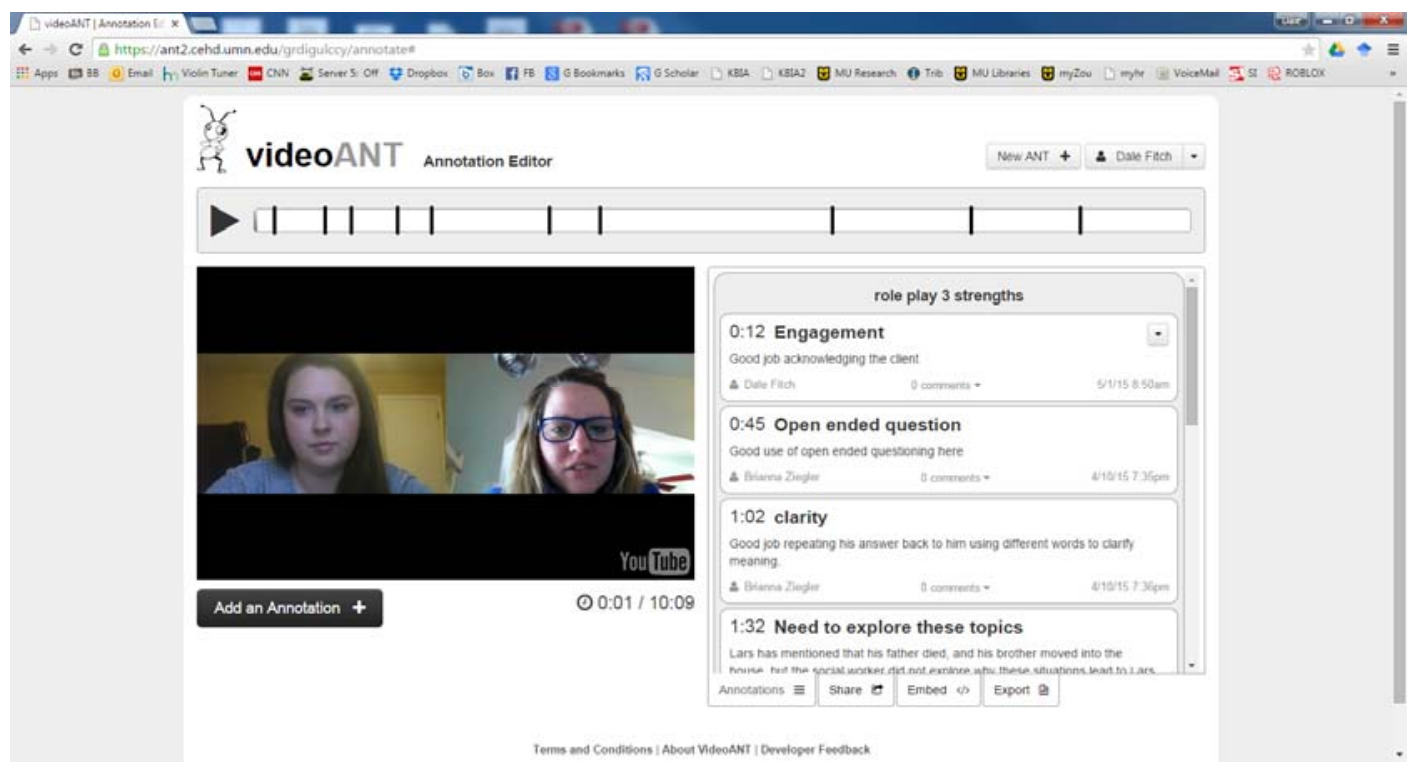

Figure 2. Screen capture of videoANT user interface.

This interface, viewable by the instructor and peers, provides an opportunity to view the video and provide feedback. Most important in this technical solution is the ability to provide annotated feedback that is time-stamped. Closer examination of the image will show that feedback provided at the 12 second mark, 45 second mark, etc., results in a hash mark on the timeline above the video. As such, a student reviewing the feedback provided by an instructor can go to those specific spots in the video to see what is referenced. Having this time-stamped annotated capability precludes the need to segment video sections into different files (Shibusawa et al., 2006) or fast-forward or reverse through the entire video.

Most importantly, the annotation feature can have other uses. For example, an instructor may ask students to perform a self-assessment of their role play performance using an established rubric at the time of assignment submission. In this manner the instructor would then evaluate how well the participants were able to assess their skills. The instructor can then provide feedback using the "Comments" feature. Alternatively, peers may be asked to provide the initial feedback with the instructor evaluating how well peers are able to note specific interaction skills. In sum, there are multiple ways to provide feedback. The role play video is accessible via the Internet, and the participants, instructor, and peers do not have to be at the same place at the same time to provide this feedback.

Taken together, the most salient features program planners will want to consider when designing or selecting an interface to facilitate role plays would include an uncluttered user experience, viewing the participants head-on, and the ability to provide time-stamped feedback.

\section{Technical Issues}

The importance of the user interface experience cannot be understated. Instructor and student feedback revealed general consensus that the web-based technologies were easy to 
use. Specifically, individuals with older laptops (6+ years) reported the technologies worked well. Users with smartphones were also able to use Zoom with ease. There were two types of occasional audio problems: a) some users reported no sound, but that was remedied by having the users check their default microphone configurations, and $b$ ) there was some degree of latency (the audio and video images were not in sync), occurring more frequently with Google Hangouts than Zoom, but also easily remedied by having the users wear headsets. Other contributing factors for the latency appeared to be the time of day the role plays occurred with 7:00 p.m. to 9:00 p.m. being the most problematic. In addition, the level of lighting in the participants' locations contributed to latency. Insufficient lighting will cause a computer's processor to work harder in order to capture the video image thus hampering overall performance. Most important to our project, even students living in rural areas with no or limited broadband access were able to use their smartphones and reported a high quality user experience with the technology. Stated otherwise, the design choice for technology selection must be a hardware/software/access choice that is accessible for students with limited bandwidth options and can accommodate older computers and multiple operating systems and devices.

\section{Costs}

Cost was one of the more important administrative aspects of the technology solution. Zoom and videoANT are free. Zoom is free for up to 25 participants. Since only two people were involved in the role plays, no costs were incurred. Zoom is also a browser add-on, so there is no software to manually install and no administrative privileges are needed to use it on university-owned equipment. The videoANT software also has no cost since it is offered freely by the University of Minnesota.

In addition, even though we used the free version of Zoom, if a social work program needed to conduct role plays that might contain client identifiable information, paid versions of Zoom are available that can provide additional privacy controls. The videoANT software, likewise, while still freely available, can be installed on a university's secure server for enhanced privacy protections. In sum, the design choices we made for our program involved no costs. Although free software may raise quality concerns, our experiences show that low-cost video sharing software can meet the needs for online social work education programs.

\section{Support}

Most helpful in our iterative approach was learning the needs of students in using the new technology. In line with existing best practices, an extensive step-by-step guide was written to direct the instructors and students through each part of the process of setting up a role play through video feedback. While most students found these guides very helpful, others did not. Because of student feedback, online video tutorials were created to demonstrate how to do each step. Once these online tutorials were introduced, no technical issues arose. It may be important to become familiar with the technology before the actual role play assignment. One student reported, "I thought [it] was relatively easy once I got my account set up and did a run through to verify that everything worked." This design choice is the one that typically gets overlooked even though "Help" buttons are found in 
most software applications. By the very fact that most people rarely use "Help" buttons beyond the first attempt (Grayling, 2002), program implementers must devote the time necessary to learn exactly what types of support are needed and in which ways they need to be delivered.

\section{Time and Effort}

Almost all of the students had prior experience doing role plays in the classroom setting. As such, they were asked to compare the two experiences in terms of the time and effort required to perform a role play. Several students reported they would not have been able to do the role play if not for online videoconferencing due to travel barriers and employment obligations. For example, one student commented,

There might be a little less time involved as it was completed without having to travel to a mutual location. It was very convenient for a single mother, someone out of town, and one traveling out of town for other appointments to coordinate a time to complete the assignment.

Similarly, a second student commented,

After I get off work and drive an hour plus to [school location] I don't feel like I can give the proper amount of attention to an assignment after class. This is a great tool to overcome that problem and still have an effective educational experience.

For these students the use of technology allowed them to participate in key learning experiences while simultaneously managing competing life events. Many of our students, particularly those enrolled in the part-time program, have a multitude of competing roles including full- and part-time work and caregiver responsibilities. Time and effort is an important consideration and frequent barrier that technology may help address. The design choice for this task actually involves an analysis of the existing classroom as opposed to any technology. Students experience location and time constraints in the traditional, oncampus classroom, and professors often must plan course time around the availability of rooms or recording equipment. These decision constraints are all taken for granted in most curriculum planning activities. Online technologies now allow us to avoid those constraints.

\section{Skill Acquisition}

Students and professors provided a range of feedback regarding the skills acquired through the online role plays. Some students found the technology "distancing" compared to a face-to-face encounter. Alternatively, other students found the encounter more "intimate" in that the pressure to "perform in front of others" was not felt. For example, one student commented,

It is definitely not as natural as in-classroom role plays, but that's to be expected. I think our actual verbal interaction was pretty comparable and I feel it is good technology to practice for the future of clinical social work. 
Another student reported,

It was an adjustment with the eye contact being difficult, though with the camera being straight on each person, it was easy to see body language, non-verbal idiosyncrasies, as well as facial expressions.

This last comment is particularly important for those concerned about technology interfering with human interactions. Online role play is different from in-person classroom experiences, but it does not appear to be so different as to prevent all nonverbal communications. However, more research is necessary.

The instructor feedback related to skills acquisition indicated that students acquired comparable skills relative to classroom students. Similar to the student feedback, the instructors reported that students were able to demonstrate engagement skills and other techniques much like their classroom counterparts. Future studies will need to more rigorously assess if any differences occur with skill acquisition.

\section{Privacy}

Even though the privacy constraints in doing a role play are no different than those of the traditional classroom, additional steps were taken in light of the online environment in which this learning activity would take place. Those steps included privacy settings within the software and the use of disclaimers.

Students were instructed how to change the default privacy settings for Google Hangouts and Zoom and, for YouTube, to change the video settings from Public to Unlisted. In addition, the role play began with the person playing the role of the social worker saying: "The following is a fictional role play - all names, places, and events are fabricated." During the role play the social worker and client referred to each other with fictional names. At the conclusion of the role play, the person playing the role of the social worker said: "The preceding was a fictional role play- all names, places, and events were fabricated." No students reported any concerns due to privacy issues. The design choices for this issue will change as often as hardware and software change, and that point must not be forgotten. However, these choices should not be limited to the conduct of online role plays. Indeed, with all types of classroom activities now having at least some online component (e.g., email, course management systems), students and faculty must continually upgrade their knowledge and skills regarding safe computing practices.

\section{New Learning Connections}

The connections some students made from this online exercise to the future of social work practice were unexpected. One student noted, "What a great way to provide counseling to those in remote locations (servicemen and women overseas?)!" Another student stated,

I like the idea of video interviews because of the convenience and learning opportunities. If a social worker could do appointments over video and they are able to record it confidentially, it would allow them to be able to watch the video afterwards to see if they might have missed something in the client's expression, 
tone, or body language. The client also might have said something important that the social worker missed during the initial interview, but noticed when watching the video.

It is understandable that social work educators have serious concerns about the use of technology in online education and social work practice. However, it appears that students not only feel comfortable with this medium but are also able to see implications for practice that may not have been imagined without their exposure to it in the online role play exercises.

Finally, the design choice for programs looking to add an online component is simply to be aware these new learning connections will extend far beyond any one role play exercise or class. Not only do students see the opportunity to use technology in new ways, but faculty will also find new ways to think about teaching and learning. When that happens, some faculty and students will be reluctant to return to the traditional way of learning if a technology-facilitated approach is viewed as preferable.

\section{Discussion}

The purpose of our project was to systematically examine the design features that needed to be considered when developing a technical solution that facilitates online role plays. Incorporating Peffers and colleagues' (2008) design science methodology allowed us to examine these features within pedagogical and organizational constraints. Doing so allowed us to be more explicit in what the technology can and cannot do and how it can serve pedagogical goals instead of limiting them. In addition, the transparency of the technology design allowed our project to be more explicit in describing how the technology mediates the acquisition of interaction skills, a very important factor in future efficacy studies for online education.

A lack of clarity regarding the mediating capacity can have unintended consequences. For example, the Google Hangout latency issue might have contributed to the findings reported by Holmes and Kozlowski (2015), yet we do not know since they did not address those issues into their article. This omission may lead some to believe that interaction skills cannot be obtained online due to technical rather than pedagogical reasons. Extending this reasoning further can be especially problematic if we then infer that potential clients should not receive services online. Not only did the students in our pilot project point out the possible contribution online therapy might make for clients who cannot access services otherwise, but randomized control trials from other fields also show that online therapy has demonstrated efficacy for depression (Andersson et al., 2005; Andersson et al., 2013; Griffiths et al., 2012; Preschl, Maercker, \& Wagner, 2011), social phobias (Berger, Hohl, \& Caspar, 2009), anxiety (Ellis, Campbell, Sethi, \& O’Dea, 2011; Hedman et al., 2014), and eating disorders (Heinicke, Paxton, McLean, \& Wertheim, 2007).

A surprising mediating role that technology played also occurred with performance anxiety issues around role plays. Our finding that students found role plays intimidating in front of a room of peers was also encountered by Shibusawa et al. (2006). Ideally, one would hope we could provide settings for students to acquire skills without the complicating factor of performing in front of others since counseling is not done in that 
manner either. Using technology as a mediator that focuses on skill acquisition may make it preferable for students to acquire skills regardless of online or on-campus settings.

Most intriguing is how the use of online technologies mediates the time constraints imposed by traditional classrooms. As noted by the instructors in our project and other researchers (Peterson, 2014; Shibusawa et al., 2006), the storage of recorded role plays on the web allows for their access at any later time in the semester for additional learning and understanding. All too often role plays are seen as one-time events, diminishing the educational capacity of the exercise. Students may not fully appreciate certain aspects of a counseling technique until it is presented in a different context. By having the role play available online, new learning may occur that would not have happened otherwise.

Finally, while studies like Peterson's (2014) are to be lauded because they report pre/post measures of competency achievement, it may be just as important to document how the use of technology is to occur. That is, how should instructors identify potential technical solutions to address the issue of online role plays amid the various software and hardware options? This article attempts to answer that question. However, in doing so it also results in other intriguing possibilities.

\section{Implications for Future Research}

The most important implication for future research is the need for more rigorous research designs in assessing student interaction skills. Our preliminary results are promising, but no generalizable claims can be made due to the lack of comparison/control groups, and lack of a random sample. However, it is important that any future efficacy study involving technology be transparent in describing the role that technology plays and how that technology fits into pedagogical goals and organizational constraints. Additionally, researchers should describe the process of using the technology including implementation procedures, ease of use, and any technical difficulties experienced.

Future students, online or not, need to be able to engage in more role play activities. One of the most paradigm-shifting outcomes from our project is getting instructors to think outside the 3-hour block of time that has historically constrained our educational activities. Asynchronous online learning completely removes that constraint and re-shifts the focus away from online teaching and toward online learning. Without the 3 -hour time constraint, all students could conceivably engage in as many role plays as pedagogically desired. Granted, this would increase workload issues for both students and instructors, but it would certainly address the need expressed by students to have more practice acquiring interaction skills prior to field placement experiences.

Finally, if our profession is to take the next step of offering social work services online, we must find the best ways to prepare students to provide those services. We must explore methods for training students to compensate for non-verbal cues that may be obscured by video technology. Becoming familiar with technology interfaces via role plays may be the first step. 


\section{References}

Andersson, G., Bergström, J., Holländare, F., Carlbring, P., Kaldo, V., \& Ekselius, L. (2005). Internet-based self-help for depression: Randomised controlled trial. The British Journal of Psychiatry, 187(5), 456-461. doi: http://dx.doi.org/10.1192/bjp.187.5.456

Andersson, G., Hesser, H., Veilord, A., Svedling, L., Andersson, F., Sleman, O., . . . Carlbring, P. (2013). Randomised controlled non-inferiority trial with 3-year followup of Internet-delivered versus face-to-face group cognitive behavioural therapy for depression. Journal of Affective Disorders, 151(3), 986-994. doi: http://dx.doi.org/10.1016/j.jad.2013.08.022

Berger, T., Hohl, E., \& Caspar, F. (2009). Internet-based treatment for social phobia: A randomized controlled trial. Journal of Clinical Psychology, 65(10), 1021-1035. doi: http://dx.doi.org/10.1002/jclp.20603

Bolger, J. (2014). Video self-modelling and its impact on the development of communication skills within social work education. Journal of Social Work, 14(2), 196-212. doi: http://dx.doi.org/10.1177/1468017313476982

Dempsey, M., Halton, C., \& Murphy, M. (2001). Reflective learning in social work education: Scaffolding the process. Social Work Education, 20(6), 631-641. doi: http://dx.doi.org/10.1080/02615470120089825

Duffy, J., Das, C., \& Davidson, G. (2013). Service user and carer involvement in roleplays to assess readiness for practice. Social Work Education, 32(1), 39-54. doi: http://dx.doi.org/10.1080/02615479.2011.639066

Ellis, L. A., Campbell, A. J., Sethi, S., \& O'Dea, B. M. (2011). Comparative randomized trial of an online cognitive-behavioral therapy program and an online support group for depression and anxiety. Journal of Cybertherapy and Rehabilitation, 4(4), 461467.

Gardner, F. (2001). Social work students and self-awareness: How does it happen? Reflective Practice, 2(1), 27-40. doi: http://dx.doi.org/10.1080/14623940120035505

Grayling, T. (2002). If we build it, will they come? A usability test of two browser-based embedded help systems. Technical Communication, 49(2), 193-209.

Griffiths, K. M., Mackinnon, A. J., Crisp, D. A., Christensen, H., Bennett, K., \& Farrer, L. (2012). The effectiveness of an online support group for members of the community with depression: A randomised controlled trial. PLOS ONE, 7(12). doi: http://dx.doi.org/10.1371/journal.pone.0053244

Hargreaves, R., \& Hadlow, J. (1997). Role-play in social work education: Process and framework for a constructive and focused approach. Social Work Education, 16(3), 61-73. doi: http://dx.doi.org/10.1080/02615479711220241

Hedman, E., El Alaoui, S., Lindefors, N., Andersson, E., Rück, C., Ghaderi, A., . . . Ljótsson, B. (2014). Clinical effectiveness and cost-effectiveness of internet- vs. 
group-based cognitive behavior therapy for social anxiety disorder: 4-year follow-up of a randomized trial. Behaviour Research and Therapy, 59, 20-29. doi:

http://dx.doi.org/10.1016/j.brat.2014.05.010

Heinicke, B. E., Paxton, S. J., McLean, S. A., \& Wertheim, E. H. (2007). Internetdelivered targeted group intervention for body dissatisfaction and disordered eating in adolescent girls: A randomized controlled trial. Journal of Abnormal Child Psychology, 35(3), 379-391. doi: http://dx.doi.org/10.1007/s10802-006-9097-9

Holmes, C., \& Kozlowski, K. (2015). A preliminary comparison of online and face-toface process groups. Journal of Technology in Human Services, 33(3), 1-22. doi: http://dx.doi.org/10.1080/15228835.2015.1038376

Levine, J. (2013). Teaching groupwork at a distance using an asynchronous online roleplay. Groupwork, 23(1), 56-72. doi: http://dx.doi.org/10.1921/1601230104

Macgowan, M. J., \& Vakharia, S. P. (2012). Teaching standards-based group work competencies to social work students: An empirical examination. Research on Social Work Practice, 22(4), 380-388. doi: http://dx.doi.org/10.1177/1049731512442249

Miller, M. D. (2014). Minds online: Teaching effectively with technology. Cambridge, MA: Harvard University Press. doi: http://dx.doi.org/10.4159/harvard.9780674735996

Moss, B. (2000). The use of large-group role-play techniques in social work education. Social Work Education, 19(5), 471-483. doi: http://dx.doi.org/10.1080/026154700435995

Peffers, K., Tuunanen, T., Rothenberger, M. A., \& Chatterjee, S. (2008). A design science research methodology for Information Systems Research. Journal of Management Information Systems, 24(3), 45-77. doi: http://dx.doi.org/10.2753/MIS0742-1222240302

Peterson, L. (2014). Using technology in peer role-play assignments to enhance competency in clinical dyadic treatment: A pilot study. Journal of Technology in Human Services, 32(1-2), 4-21. doi: http://dx.doi.org/10.1080/15228835.2014.885403

Petracchi, H. E. (1999). Using professionally trained actors in social work role-play simulations. Journal of Sociology \& Social Welfare, 26(4), 61-69.

Petracchi, H. E., \& Collins, K. S. (2006). Utilizing actors to simulate clients in social work student role plays: Does this approach have a place in social work education? Journal of Teaching in Social Work, 26(1-2), 223-233.

Petrovich, A. (2004). Using self-efficacy theory in social work teaching. Journal of Social Work Education, 40(3), 429-443.

Preschl, B., Maercker, A., \& Wagner, B. (2011). The working alliance in a randomized controlled trial comparing online with face-to-face cognitive-behavioral therapy for 
depression. BMC Psychiatry, 11(1), 189-198. doi: http://dx.doi.org/10.1186/1471244X-11-189

Rakovshik, S. G., McManus, F., Westbrook, D., Kholmogorova, A. B., Garanian, N. G., Zvereva, N. V., \& Ougrin, D. (2013). Randomized trial comparing Internet-based training in cognitive behavioural therapy theory, assessment and formulation to delayed-training control. Behaviour Research and Therapy, 51(6), 231-239. doi: http://dx.doi.org/10.1016/j.brat.2013.01.009

Reicherzer, S., Coker, K., Rush-Wilson, T., Buckley, M., Cannon, K., Harris, S., \& Jorissen, S. (2012). Assessing clinical mental health counseling skills and practice standards in distance education. Counseling Outcome Research and Evaluation, 3(2), 104-115. doi: http://dx.doi.org/10.1177/2150137812452558

Reid, W. J., \& Hanrahan, P. (1982). Recent evaluations of social work: Grounds for optimism. Social Work, 27(4), 328-340.

Shibusawa, T., VanEsselstyn, D., \& Oppenheim, S. (2006). Third Space: A web-based learning environment for teaching advanced clinical practice skills. Journal of Technology in Human Services, 24(4), 21-33. doi: http://dx.doi.org/10.1300/J017v24n04_02

Vapalahti, K., Marttunen, M., \& Laurinen, L. (2013). Online and face-to-face role-play simulations in promoting social work students argumentative problem-solving, 8(1). Retrieved from http://jesw.no/local/media/jcsw/docs/jesw issue_2013_1_02_article.pdf

Zhang, L., Gillies, M., Dhaliwal, K., Gower, A., Robertson, D., \& Crabtree, B. (2009). eDrama: Facilitating online role-play using an AI actor and emotionally expressive characters. International Journal of Artificial Intelligence in Education, 19(1), 5-38.

\section{Author note}

Address correspondence to: Dale Fitch, School of Social Work, University of Missouri at Columbia, 703 Clark Hall, Columbia, MO 65211, fitchd@missouri.edu, 573-884-7405. 